\title{
Tiotropium Bromide: An Update
}

\author{
Josep Lluis Heredia* \\ S. Pneumologia, Hospital Mutua de Terrassa, c/ Dr. Robert 5, 08221 Terrassa, Barcelona, Spain
}

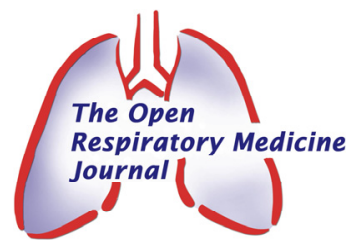

\begin{abstract}
Tiotropium bromide is a once-daily inhaled anticholinergic bronchodilator. It works by blocking the muscarinic receptors in airway smooth muscle. Tiotropium has a wide therapeutic margin, due to its poor gastrointestinal absorption and its very low systemic bioavailability. The drug is mainly indicated in COPD patients. Clinically relevant outcomes such as significant improvements in spirometry, hyperinflation, dyspnea, heath status, acute exacerbations and mortality have been consistently observed in tiotropium clinical trials, and the drug has been shown to reduce the risk of mortality due to cardiac-vascular disease and respiratory failure. The main side effect reported is dryness of the mouth. Some subgroups of asthmatics also seem to respond to anticholinergic drugs: among them, those with the Arg/Arg genotype for the $\beta 2$-adrenergic receptor and those with a high percentage of neutrophils in sputum.
\end{abstract}

Keywords: Tiotropium bromide, COPD, lung function, COPD mortality, COPD exacerbations, quality of life.

\section{INTRODUCTION}

Chronic obstructive lung disease (COPD) is a widespread chronic disease that mainly affects long-term smokers. As its name indicates, it is characterized by airway irreversibility. To date, the results of treatment for this disease have been relatively disappointing and no drug has proved able to reverse, or even to check, its development. In this paper we review the properties, pharmacological and clinical effects of tiotropium bromide, the latest drug to come on the market for treatment of chronic lung obstruction.

\section{DRUG CHARACTERISTICS}

Tiotropium bromide is a synthetic quaternary anticholinergic agent approved for maintenance therapy in stable COPD. It has two important properties: it is functionally selective for specific muscarinic receptors that mediate airway smooth-muscle contraction, and it has a long duration of action, making it well suited for once-daily dosing. Tiotropium works by blocking the muscarinic receptors for the neurotransmitter acetylcholine (Ach), which is released from cholinergic nerve endings in the airways. As tiotropium bromide is electrically charged, it is not absorbed by the gastrointestinal tract and does not pass the blood-brain barrier. This means that it does not have characteristic side effects of anticholinergic agents, particularly those affecting the central nervous system.

\section{MUSCARINIC RECEPTORS IN THE AIRWAYS AND TIOTROPIUM BROMIDE}

Three muscarinic receptor subtypes have been found in human airways, with different functions: $\mathrm{M}_{1}, \mathrm{M}_{2}$ and $\mathrm{M}_{3}$ [1]. Autoradiographic mapping has shown that these receptors are mainly localized in the smooth muscle of all airways, although they reach their highest density in the proximal airways and in submucosal glands [2].

*Address correspondence to this author at the S. Pneumologia, Hospital Mutua de Terrassa, c/ Dr. Robert 5, 08221 Terrassa, Barcelona, Spain;

Tel: 937365050; Fax: 937836631; E-mail: joseplluisheredia@comb.es
$\mathrm{M}_{1}$ receptors are localized in parasympathetic ganglia in the airway, where they function as regulators of ganglionic transmission (Fig. 1). Preganglionic nerves release Ach, which acts on th nicotinic receptors of the ganglionic cells to activate postganglionic nerves. $M_{1}$ receptors facilitate neurotransmission through these ganglia, thereby enhancing the cholinergic bronchoconstrictor reflex [3]. Therefore, blocking $\mathrm{M}_{1}$ receptors will be beneficial in COPD patients.

$\mathrm{M}_{2}$ receptors are located on cholinergic nerve endings and act as autoreceptors which inhibit acetylcholine release from those nerve terminals [4], thereby providing feedback inhibition (Fig. 1). Drugs block $\mathrm{M}_{2}$, increasing Ach release, and thus increasing bronchoconstrictor responses.

$\mathrm{M}_{3}$ receptors are expressed in the smooth muscle of all airways (Fig. 1). The bronchoconstrictor response to cholinergic nerve stimulation and cholinergic agonists is mediated by $\mathrm{M}_{3}$ [5]. These receptors also mediate mucus secretion in response to cholinergic agonists [6]. For this reason, blockade of $\mathrm{M}_{3}$ receptors is the main objective of anticholinergic therapy in COPD. The major side effects of anticholinergic drugs dry mouth, glaucoma, and urinary retention - are all mediated by $M_{3}$ receptors, so their frequency cannot be reduced.

Therefore, optimal inhibition of parasympathetic activity may be achieved by selective antagonism of the $\mathrm{M}_{3}$ and $\mathrm{M}_{3}$ receptors, sparing the $\mathrm{M}_{3}$ receptors. Tiotropium bromide dissociates more slowly from M1 and M3 receptors than M2 receptors and for this reason has kinetic selectivity [7]; because of its sustained activity, once-daily administration is possible. Tiotropium bromide binds to muscarinic receptors with high affinity and is approximately 10 times more potent than ipratropium bromide in binding to human lung muscarinic receptors [8]. Ipratropium bromide and oxitropium bromide are nonselective blockers; consequently, they block $\mathrm{M}_{2}$ receptors, thereby increasing Ach release at nerve endings, which may reduce the degree of blockade or the duration of action [4].

It has been demonstrated that the slow dissociation of tiotropium bromide from target protein is a key factor in its 


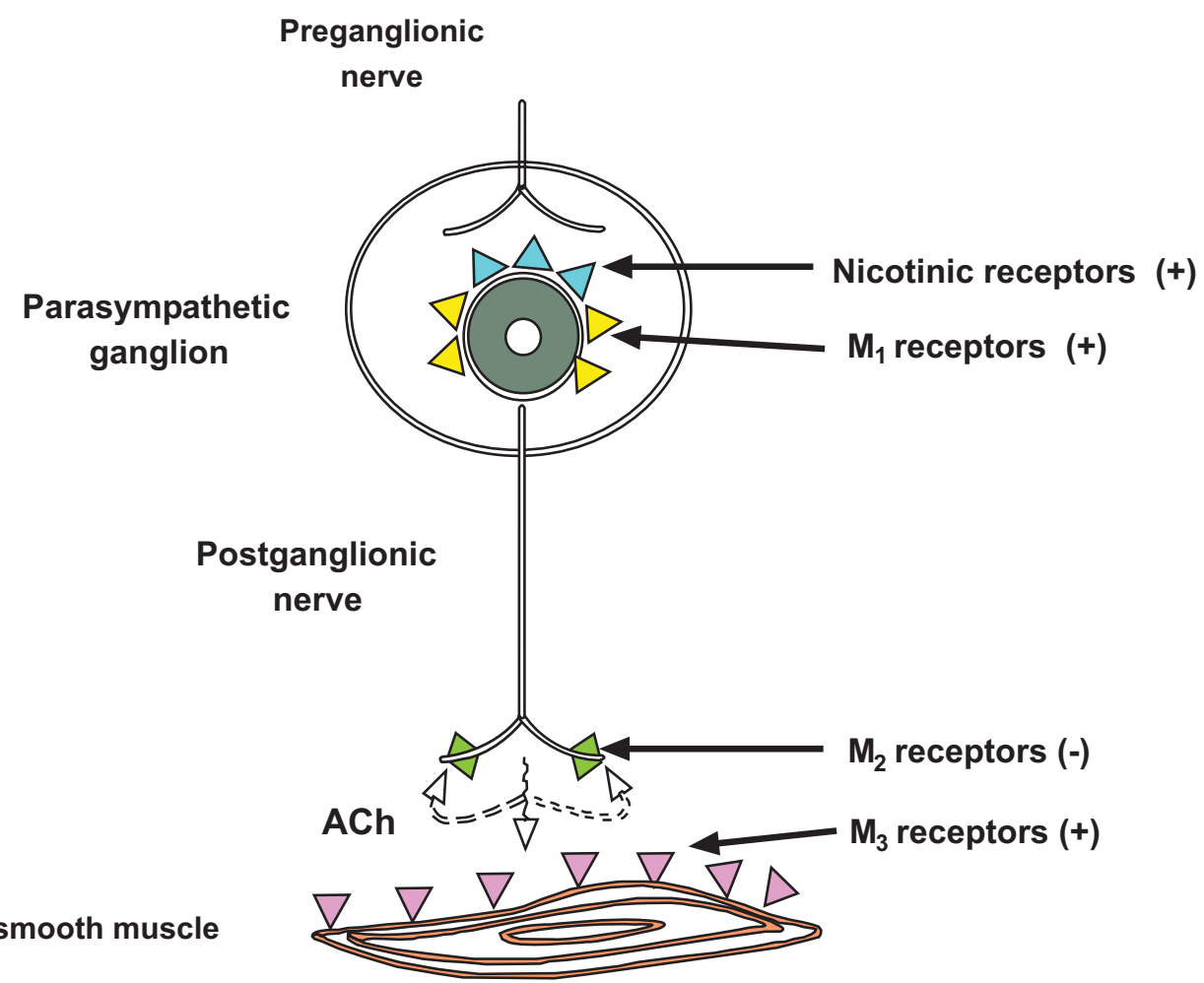

Fig. (1). Muscarinic receptor subtypes in airways. M1 are localized to parasympathetic ganglia. M2 on postganglionic cholinergic nerve terminals inhibit the release of Ach. M3 that constrict airway smooth muscle. Adapted from Barnes PJ [15].

long duration effect [7]. Though the two compounds have similar pharmacokinetic profiles, tiotropium's duration of action is more than 24-h, while ipratropium action lasts only six hours [9]. Studies using recombinant receptors have shown that tiotropium has a much slower rate of dissociation from $\mathrm{M}_{3}$ muscarinic receptors than ipratropium [10], and conclude that this feature determines the difference in duration of action between the drugs [7].

The approved dose of tiotropium is $18 \mu \mathrm{g} q d$, preferably administered in the morning [11]. As bronchodilation tends to increase over the first week of daily administration, this dose is best used on a regular daily basis. Since tiotropium may take several hours to reach its peak effect, it is not recommended for rapid relief of dyspnea. A bronchodilator reversibility test prior to prescription does not predict its long-term benefits [12].

Tiotropium has been shown to reduce the frequency of exacerbations, but its effect on airway inflammation is unclear. A placebo-control trial investigating its effect on inflammation parameters such as sputum and serum cytokines found an association with a reduced frequency of exacerbation, but there was no difference in airway or systemic inflammation [13]. A recent study [14] proposes that tiotropium may have a beneficial influence on airway remodeling in chronic airway diseases through its antiproliferative effects on fibroblasts and myofibroblasts.

\section{THE ROLE OF TIOTROPIUM IN THE MANAGE- MENT OF COPD}

There is some evidence that the cholinergic tone of the airways is increased in patients with COPD [16]. In fact vagal cholinergic tone is the main reversible element of airway obstruction in COPD, and its effects are exaggerated by geometric factors due to narrowed airways, because airway resistance is inversely proportional to the fourth power of the airway radius [17].

Tiotropium significantly improves bronchodilation, hyperinflation, dyspnea, health status, exacerbations and mortality in COPD patients, but it does not decrease the rate of FEV1 decline in COPD.

\section{BRONCHODILATION}

The degree of acute improvement in spirometry indices after bronchodilator inhalation varies among COPD patients, and depends on the type and dose of bronchodilator as well as the timing of administration. The Global Initiative for Chronic Obstructive Lung Disease (GOLD) defines COPD as a disease characterized by a partially reversible airflow limitation [18]. Patients with COPD are commonly thought to present a lower acute bronchodilator response than asthmatics, although a high percentage of patients with COPD respond to high doses of $\beta_{2}$ adrenergic receptors [19]. Moreover, more than half of COPD patients who do not significantly respond to $\beta 2$ adrenergic receptors have positive bronchodilator tests when high doses of inhaled anticholinergics are administered [20]. A recent trial in a large cohort of patients with moderate-to-very-severe COPD found significant increases in lung function in most patients who received $80 \mu \mathrm{g}$ ipratropium followed by $400 \mu \mathrm{g}$ salbutamol. The percentage of patients considered as responders differed depending upon the criterion applied [21]. Almost two-thirds $(65.6 \%)$ of patients met at least one common criterion for FEV1 responsiveness following acute administration of bronchodilators [22].

FEV1 has been shown to rise slowly after tiotropium administration, reaching a peak between 1 to $3 \mathrm{~h}$ after the 
inhalation. The peak response is followed by a plateau significantly higher than placebo, lasting up to $32 \mathrm{~h}$ [9].

Tiotropium has shown an effective bronchodilation effect following single administrations of doses of between 10 and $80 \mathrm{mg}$ [9]. All subsequent studies have used a daily dose of $18 \mathrm{mg}$. After drug withdrawal, patients' FEV1 gradually returned to baseline levels over a period of approximately 3 weeks, indicating that the drug exerted a prolonged effect [23].

Repeated daily use of tiotropium offers persistent bronchodilation. The FEV1 24 hours post-dose (and before the next dose), its "trough" value, progressively increases over the first few days of regular administration. Van Noord et al. [24] found that the trough FEV1 increased by $0.19 \mathrm{~L}(18 \%$ above the initial baseline) after 8 days of daily administration, most of this increase having occurred by the second day. Trough FVC continued to rise daily during the first week and had increased by $0.67 \mathrm{~L}(27 \%$ above its initial baseline) by day 8 .

The results of large long-term trials indicate that tiotropium administered once daily raises the trough FEV1 by 0.1 to $0.15 \mathrm{~L}$, and raises the peak FEV1 by a further 0.15 to 0.20 L. In both cases, its effect is significantly higher than that of either ipratropium administered four times daily or salmeterol administered twice daily. No loss of efficacy was seen over the course of one year of regular treatment with tiotropium. Therefore, it appears that the difference at the end of the trial may be due, at least to some extent, to the fact that the response to tiotropium was maintained, whereas the response to salmeterol decreased over the course of the study, suggesting the development of tachyphylaxis [25-28]

In the UPLIFT study [29], the mean FEV1 value in the tiotropium group after the bronchodilation test showed a significant improvement compared with the placebo group, which was maintained throughout the study. This improvement ranged from 47 to $65 \mathrm{ml}$ after bronchodilation $(\mathrm{p}<0.001)$ (Fig. 2). The tiotropium group also showed a significant improvement in the FEV1 before bronchodilation, ranging from 87 to $103 \mathrm{ml}(\mathrm{p}<0.001)$ (Fig. 2). But in patients with stable COPD there was little difference in bronchodilation when adding higher than conventional doses of salbutamol or ipratropium bromide to tiotropium. This is an interesting finding, especially for COPD patients suffering from cardiovascular co-morbidities [30]. On the other hand, in patients with COPD the addition of formoterol once or twice daily to tiotropium once daily improves airflow obstruction, resting hyperinflation, and the use of rescue salbutamol [31]. No such improvement was found when we added salmeterol to tiotropium [32].

\section{HYPERINFLATION}

In COPD patients, hyperinflation is reflected by a significant increase in static lung volumes. Lung volume changes correlate better with impairment of patient functional capabilities than airflow limitations [33]. The systematic use of tiotropium may produce a significant reduction in lung inflation.

The inspiratory capacity (IC) is a parameter that can be measured by spirometry and its increase indirectly reflects a decrease in hyperinflation $[34,35]$. In patients with COPD receiving 4-week treatment with tiotropium versus placebo the functional residual capacity was substantially reduced and IC was increased in the treated group, indicating a reduction in hyperinflation that did not occur in the placebo group [36] (Fig. 3). Another clinical trial found that the reduction in hyperinflation led to an increase in the tidal volume during constant work-rate cycle ergometry, with an improvement in endurance time of approximately $21 \%$. The dyspnea index also improved after six weeks of treatment [37].

Recently, Gelb et al. studied the protection of tiotropium against dynamic hyperinflation in COPD phenotypes. Emphysema was evaluated by high-resolution thin-section lung scan. Spirometry (including inspiratory capacity) was meas-

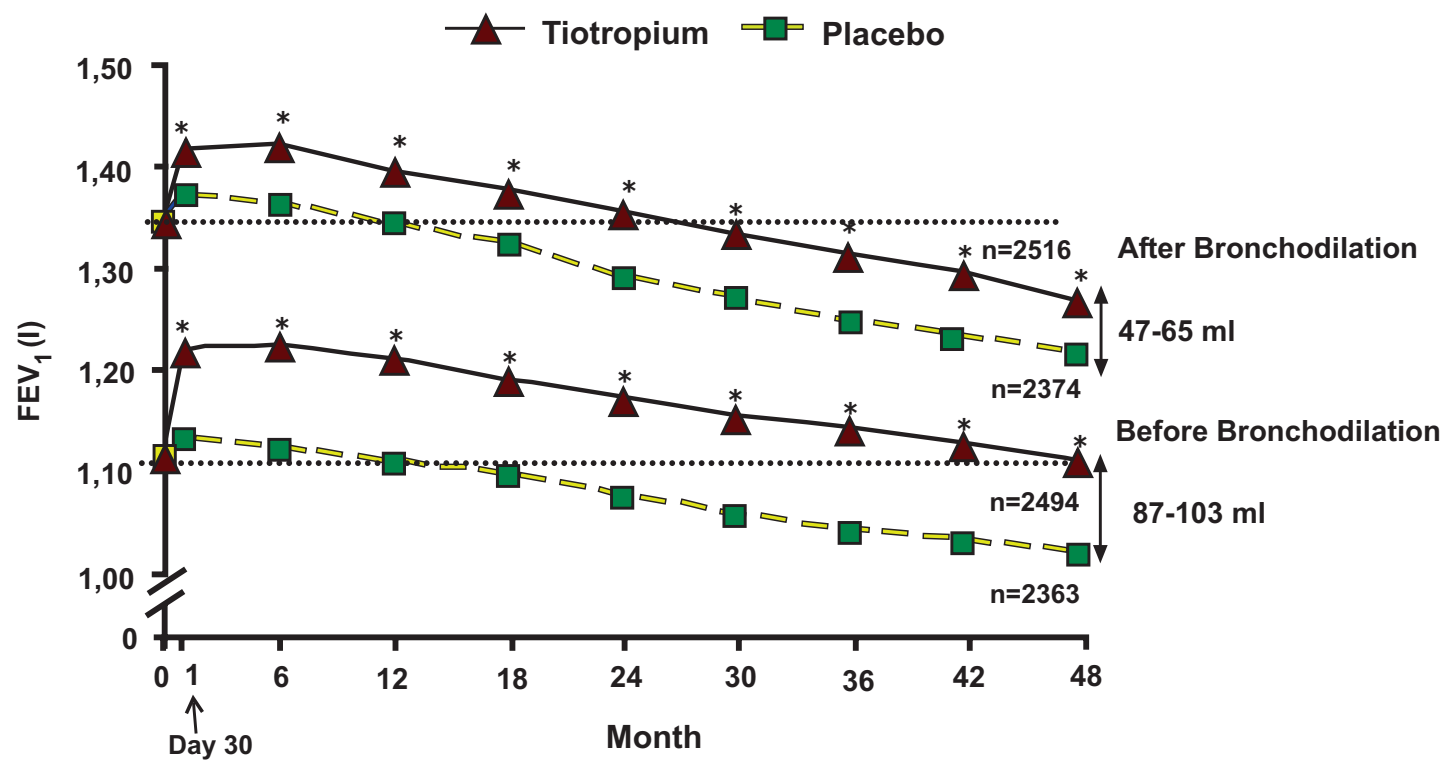

${ }^{*} P<0,001$ versus control

Fig. (2). Mean forced expiratory volume in 1 second before and after bronchodilation from day 30 to the end of the study. From Tashkin et al. [29]. 
ured before and immediately after metronome-paced hyperventilation to induce dynamic hyperinflation. Tiotropium increased IC in moderate-severe COPD, independently of the severity of lung emphysema. Despite bronchodilation and lower resting lung volume, tiotropium did not decrease the induced dynamic hyperinflation, which was also independent of underlying emphysema [38].

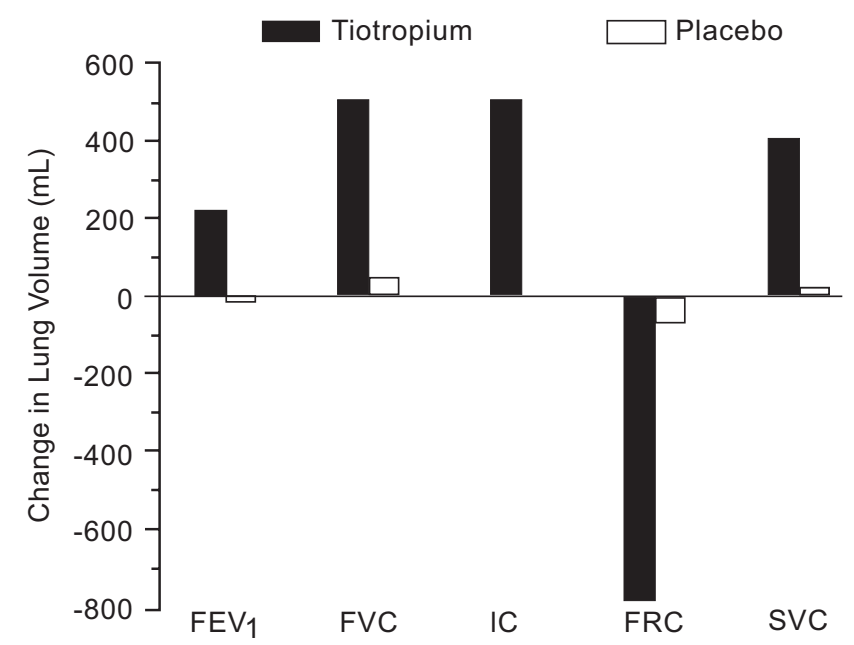

Fig. (3). Changes in lung volumes and spirometry following treatment with tiotropium or placebo after 4 weeks. All differences between treatments were significant $(\mathrm{p}<0.01)$. From Celli et al. [36].

\section{DYSPNEA}

In COPD patients, dyspnea correlates more closely with hyperinflation than FEV1 [33, 34]. The effect of tiotropium on this symptom has been measured by Mahler's transition dyspnea index (TDI) [39] for the dyspnea incurred by activities of daily living in COPD. The improvement in TDI in patients receiving tiotropium has been shown to be statistically higher than placebo and ipratropium at all time points over a 12-month period and tends to increase as treatment progresses $[25,26]$. In the studies comparing salmeterol versus tiotropium, the improvement in TDI with tiotropium was greater than with salmeterol [27-28] although this difference only reached statistical significance in one study [27]. COPD symptoms can be measured indirectly with the use of a rescue short-acting $\beta_{2}$-agonist. A treatment that effectively reduces symptoms should also reduce the need for rescue medication; studies have shown that tiotropium performs better than both placebo and ipratropium $[25,26]$.

Pulmonary rehabilitation has been shown to improve exercise tolerance as well as dyspnea $[40,41]$. In a placebocontrolled trial, Casaburi et al. [42] tested the hypothesis that improvement in ventilatory mechanics resulting from tiotropium treatment may enhance patients' training of muscles involved in deambulation and therefore increase exercise tolerance and the benefits of pulmonary rehabilitation. In that study, tiotropium in combination with pulmonary rehabilitation improved endurance of a constant work-rate treadmill task and produced clinically significant improvements in dyspnea and health status compared with pulmonary rehabilitation alone. In addition, improvements with tiotropium were sustained for three months after completion of pulmonary rehabilitation [42].

\section{HEALTH STATUS}

The effects of tiotropium on health status have been measured in several studies. The St. George's Respiratory Questionnaire score, measured in long-term studies, improved significantly with tiotropium treatment compared to baseline, placebo $[25,27,28]$ or ipratropium [26], but not compared to sameterol [27, 28].

In the one-year tiotropium trials using The Medical Outcomes Study Short Form-36, a generic health status instrument, the domains of role-physical and physical health summary scores significantly improved in the tiotropium group compared to the control groups [25-28].

In the UPLIFT study [29], 2478 patients treated with tiotropium and 2337 patients receiving placebo were included.

The treated group showed significant differences at all time points for the mean absolute change in the SGRQ total score, although the differences were not considered to be clinically significant. However, a higher proportion of patients in the tiotropium group compared to the placebo group had an improvement of four points or more in the SGRQ total scores from baseline at the end of the fourth year of treatment (Fig. 4).

\section{ACUTE EXACERBATIONS}

Late stage COPD is characterized by increased frequency and severity of exacerbations, which account for most of the condition's economic burden. Exacerbations are associated with worse prognosis and increased mortality, especially those that require hospital admission [43].

The effect of tiotropium treatment on the incidence of acute exacerbations has been considered as a secondary outcome in several studies. Modifying the criteria of Anthonisen et al. [44], exacerbations in the tiotropium studies were defined as an increase in two or more respiratory symptoms for at least three days. Casaburi et al. [25] enrolled 921 patients with stable COPD in two identical randomized oneyear double-blind placebo-control studies, and found significantly fewer exacerbations in the tiotropium group than in the placebo group ( $20 \%$ reduction). There was a significant increase in the time to first exacerbations in the tiotropium group compared to placebo. The proportion of patients experiencing at least one COPD exacerbation was lower in the tiotropium group $(36 \%)$ than in the placebo group $(42 \%)$ ( $14 \%$ reduction, $p<0.05)$. In addition, significantly fewer hospitalizations were associated with exacerbations in the tiotropium cohort compared to the placebo group (47\% reduction). The proportion of patients hospitalized for exacerbations was lower in the tiotropium group than in the placebo group ( $41 \%$ reduction, $\mathrm{p}>0.05)$.

Another trial [28] recorded exacerbations in 1207 patients with COPD during six months' treatment with tiotropium, salmeterol, or matching placebos. Compared with placebo, tiotropium, but not salmeterol, was associated with a delay in the onset of the first exacerbation. Fewer COPD exacerbations/patient-year occurred in the tiotropium group than in the placebo group $(\mathrm{p}<0.05)$; there were no differences between the salmeterol and the placebo groups. The tiotropium group showed 0.10 hospital admissions per patientyear per COPD exacerbation, compared with rates of 0.17 


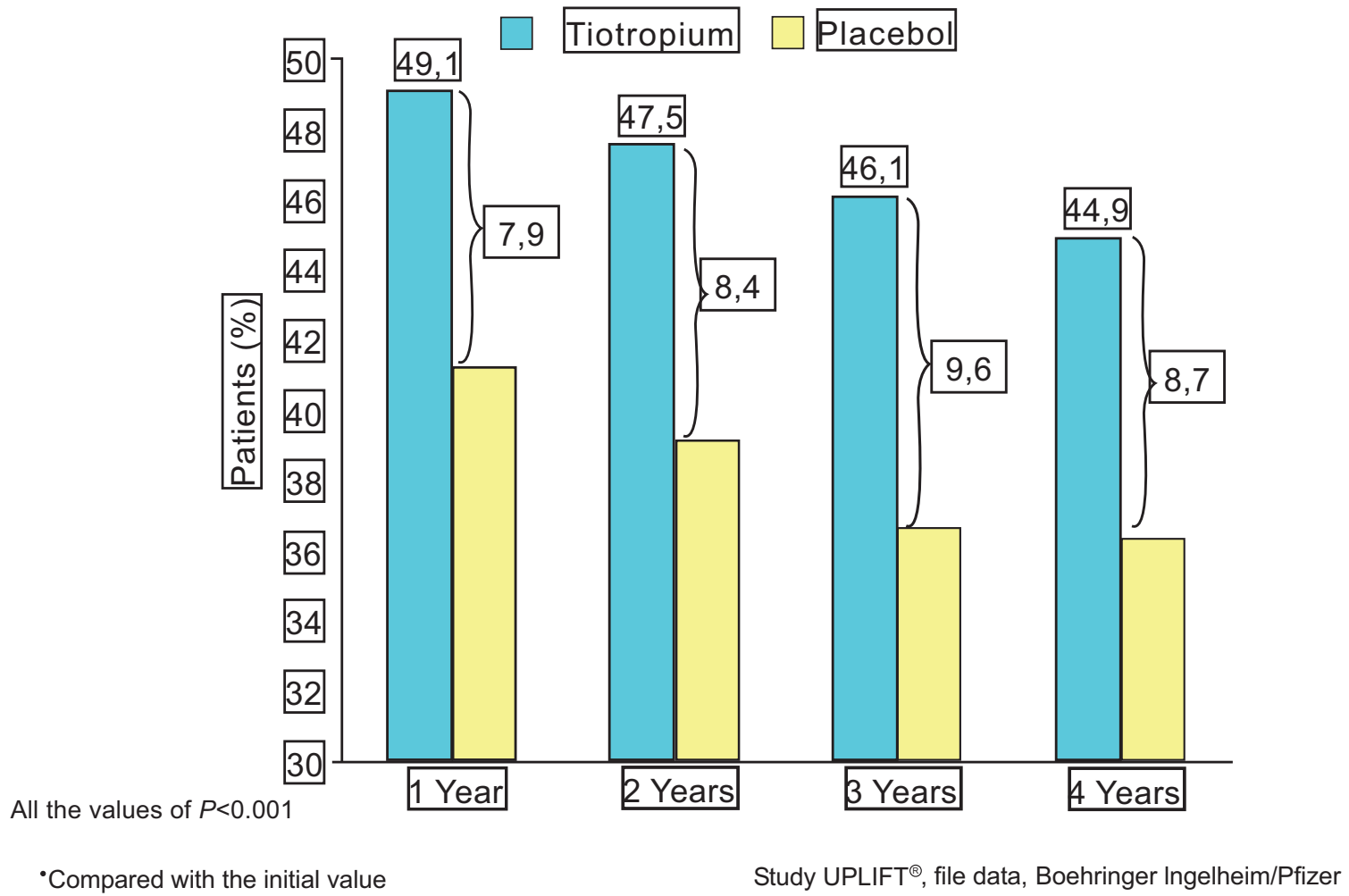

Fig. (4). Tiotropium significantly increases the percentage of patients with an improvement $\geq 4$ units in the total score of the SRGQ*. File data, Boehringer Ingelheim/Pfizer.

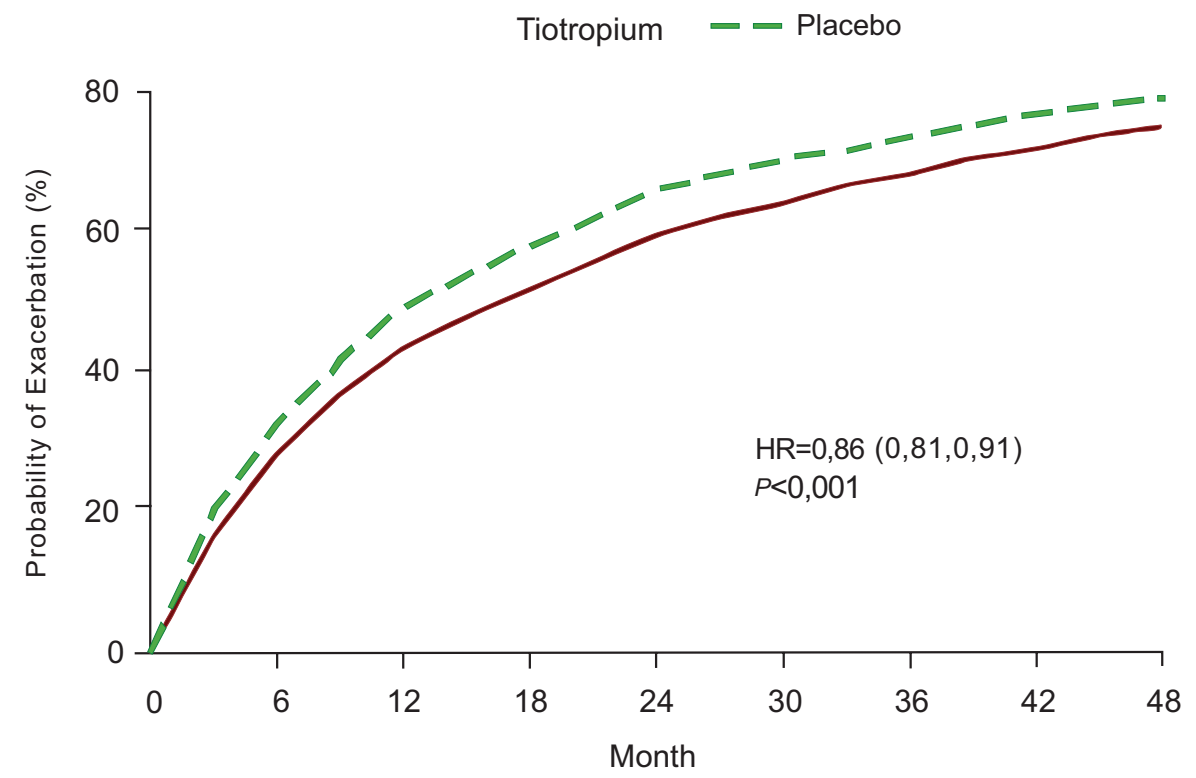

Fig. (5). Kaplan- Meier curves show the cumulative incidence estimate of the probability of COPD exacerbation at day 1470 . All patients who received at least one dose of a study drug were included in the analysis. From Tashkin et al. [29].

for salmeterol and 0.15 for placebo (non-significant differences).

The INSPIRE study [45] was the first large-scale trial to evaluate the impact of two different treatment approaches tiotropium or the combination using salmeterol and fluticasone propionate - on COPD exacerbations over a 2-year period. Methodological issues need to be considered when interpreting these results (see the mortality section). The estimated overall rates of exacerbations were 1.28 per year with the combination and 1.32 per year for tiotropium; the ratio $(0.967)$ indicated that there was no difference between the rates. The incidence of exacerbations requiring hospitalizations was $16 \%$ for salmeterol and fluticasone propionate, and $13 \%$ for tiotropium.

Two meta-analyses evaluating the effectiveness of tiotropium bromide compared to placebo, ipratropium bromide or a long-acting beta-agonist for the treatment of stable COPD patients showed that tiotropium notably reduced the exacerbations and related hospitalizations compared with placebo, 
but no statistical differences were found with respect to the

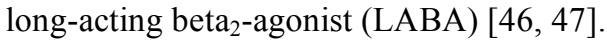

Two recent trials have evaluated the potential benefits of associating tiotropium with LABA and inhaled corticosteroids. Aaron et al. [32] report the results of the first clinical study in moderate to severe COPD after one year of followup in three groups of patients receiving tiotropium plus placebo, tiotropium plus salmeterol and tiotropium plus fluticasone-salmeterol. Similar proportions of patients experienced an exacerbation across all three groups, but those who received tiotropium plus fluticasone-salmeterol presented lower levels of COPD and all-cause hospitalizations compared with those who received tiotropium plus placebo. The addition of salmeterol to tiotropium had no effect on hospitalization rates compared to tiotropium alone. A limitation of the study is the sizable proportion of patients (approximately $40 \%$ ) who did not receive the assigned treatment throughout the study.

In the UPLIFT study, exacerbations were considered a secondary outcome [29]. The trial compared four years of therapy with either tiotropium or placebo in patients with COPD who were permitted to use all respiratory medications except inhaled anticholinergic drugs. Tiotropium was associated with a $14 \%$ reduction in the mean number of exacerbation $(p>0.001)$. The drug was associated with a significant delay in the time to the first hospitalization for an exacerbation (Fig. 5). Tiotropium was also associated with a significant delay in the time to the first exacerbation: a median of 16.7 months (95\% CI: 14.9 to 17.9 ) compared with one of 12.5 months (95\% CI: 11.5 to 13.8$)$ in the placebo group.

\section{MORTALITY}

In patients with COPD, all-cause mortality significantly decreases after smoking cessation. Mortality did not significantly differ in patients receiving ipratropium bromide or placebo [48]. Comparing four groups of patients receiving almeterol, fluticasone propionate, both drugs or placebo with death from any cause as the primary outcome, the TORCH study [49] found all-cause mortality rates to be similar in the four arms.

Mortality was a secondary outcome in a 104-week long trial [45] comparing the clinical efficacy of treatment with a fixed combination of salmeterol/fluticasone propionate and tiotropium bromide. Mortality was significantly lower in the salmeterol/fluticasone propionate group: $3 \%$ of patients in this group died, compared with $6 \%$ in the tiotropium group $(p=0.032)$. However, methodological issues need to be considered when interpreting these results [50]. In this study [45] the design imposed discontinuation of inhaled corticosteroids followed by a 2 -week run-in of oral prednisolone and salmeterol prior to randomization, which may have affected outcomes [51]. Other effects were likely due to the abrupt interruption of the run-in regimen. Another methodological problem that hampers the interpretation of the results is the incomplete follow-up of patients, which affects the intent-totreat analysis.

Two recent trials have shown that tiotropium reduces mortality. A longitudinal, population-based cohort study was conducted to compare the effect of tiotropium use and LABA use/OK? on all-cause mortality in patients with COPD [52]. Patients included individuals aged 65 or older discharged from hospital with a diagnosis of COPD. The effect of receiving a prescription for tiotropium compared to a LABA on all-cause mortality at 180 days post-hospital discharge was eliminated by controlling the potential confounders. Data from 7218 eligible patients were analyzed. Of these, 1046 (14.5\%) died in the follow-up period. Patients who received tiotropium were $20 \%$ less likely to die than those receiving a LABA (hazard ratio $0.80,95 \%$ CI 0.70 to 0.93 ).

In the UPLIFT study [29], vital-status information was available after a 45 month follow-up for $98 \%$ of patients in the tiotropium and for $97 \%$ in the placebo group (including patients who discontinued treatment). Tiotropium significantly reduced mortality. Nine hundred and twenty-one patients died: $14.4 \%$ in the tiotropium group and $16.3 \%$ in the placebo group (hazard ratio, $0.87 ; 95 \% \mathrm{CI}: 0.76$ to 0.99 ) (Fig. 6).

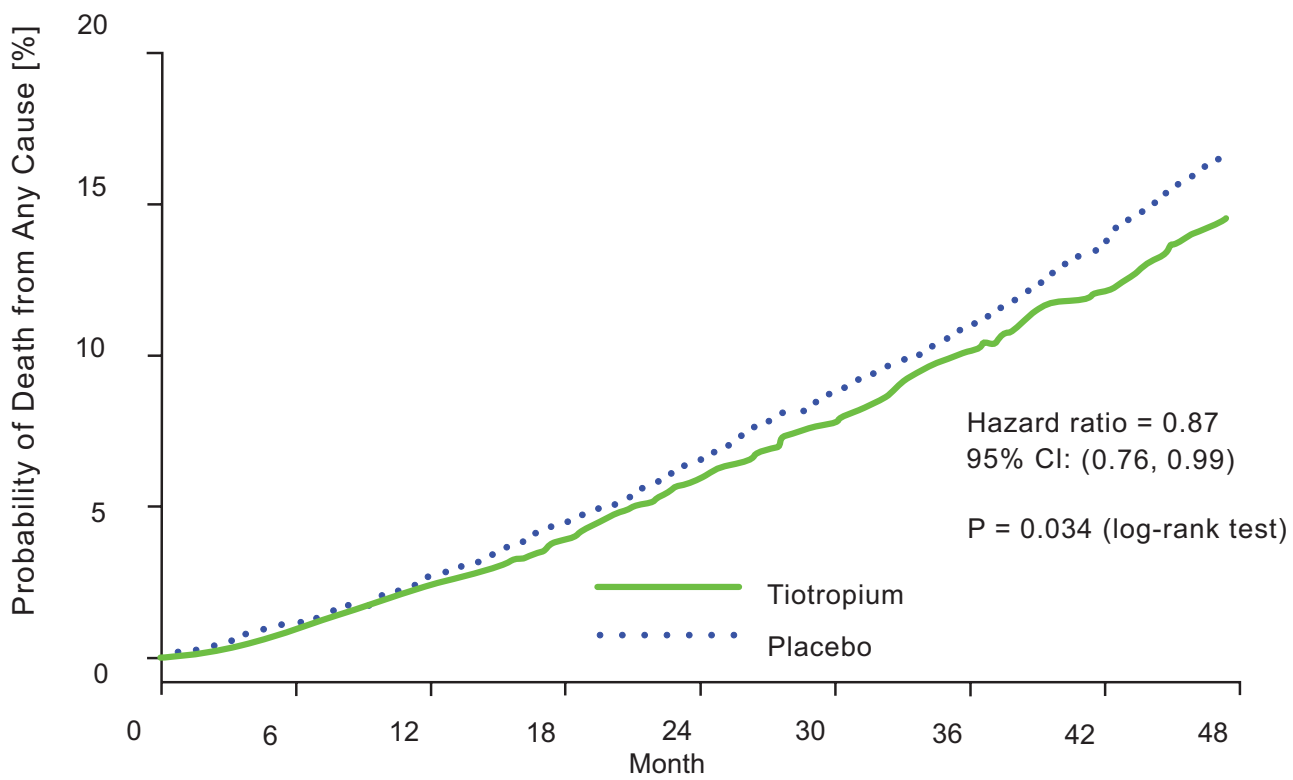

Fig. (6). Kaplan-Meier estimates of the probability of COPD death from any cause. From Tashkin et al. [29]. 


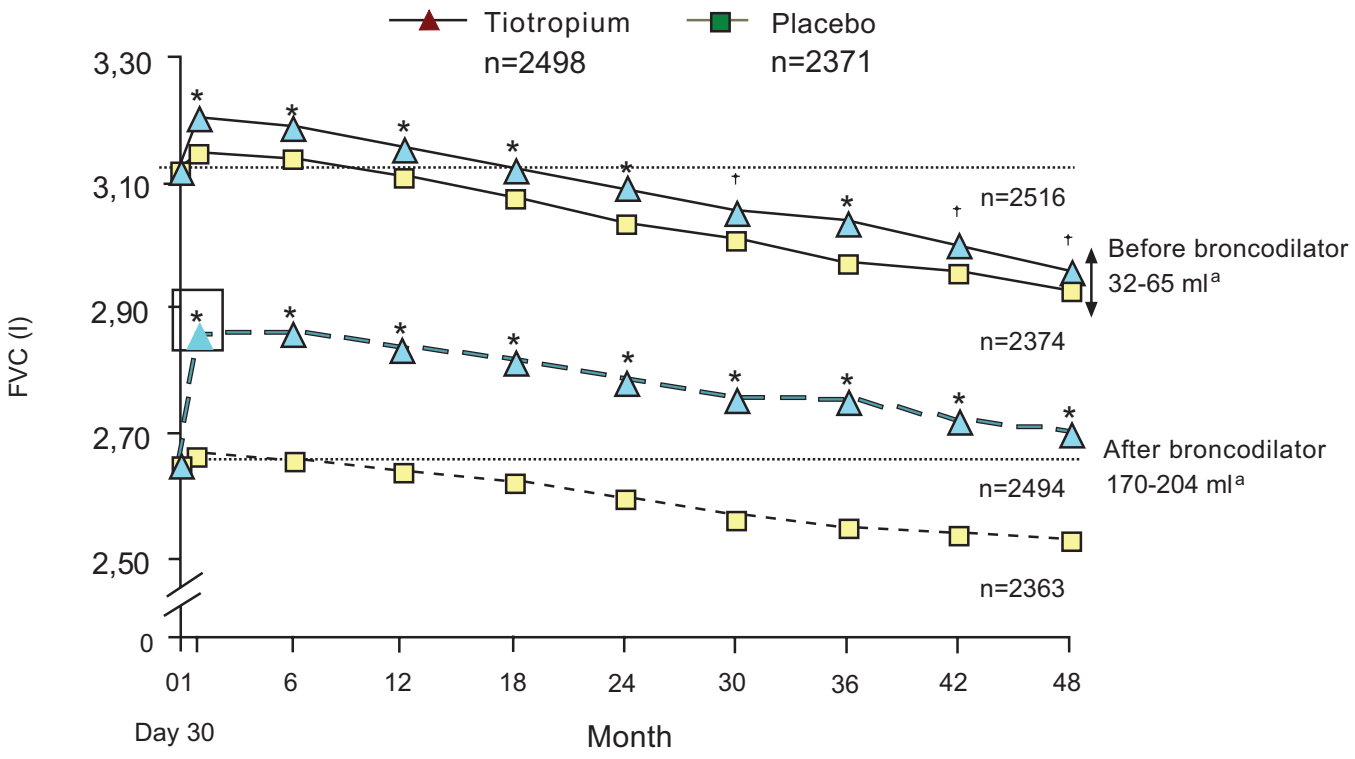

${ }^{*} P<0,0001 ;{ }^{\dagger} P<0,05$ versus control

Fig. (7). Mean forced vital capacity in before and after bronchodilation from day 30 to the end of the study. From Tashkin et al. [29].

\section{RATE OF DECLINE IN LUNG FUNCTION}

With the exception of smoking cessation, no intervention has been shown to decrease the rate of FEV1 decline in COPD [53]. Two identical 1-year, randomized, double blind, double-dummy studies involving 535 patients with COPD showed a sustained improvement in lung function. Tiotropium (18 $\mu \mathrm{g}$ once daily) increased trough FEV1 by $120 \mathrm{ml}$ by the end of the trial, whereas treatment with ipratropium (40 $\mu \mathrm{g} 4$ times daily) was associated with a $30-\mathrm{ml}$ reduction in trough FEV1 [26]. A post hoc analysis was performed using data from 921 patients [54]. The change in trough FEV1 was $-12.4 \mathrm{ml} / \mathrm{yr}$ in the tiotropium group compared with $-58.0 \mathrm{ml} / \mathrm{yr}$ in the placebo group $(\mathrm{p}=0.005)$. Similar results were observed in both former and current smokers. In former smokers, the change in trough FEV1 was $-17.0 \mathrm{ml} / \mathrm{yr}$ with tiotropium and $-67.9 \mathrm{ml} / \mathrm{yr}$ with placebo $(\mathrm{p}=0.011)$,

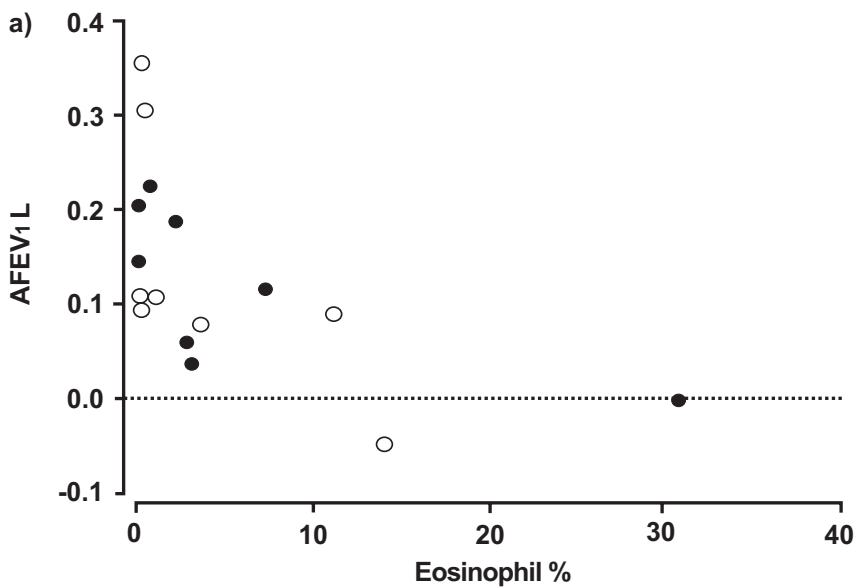

whereas in smokers the changes in trough FEV1 were -3.8 $\mathrm{ml} / \mathrm{yr}$ and $-40.5 \mathrm{ml} / \mathrm{yr}$ respectively $(\mathrm{p}=0.19)$. The lack of statistically significant differences for FEV1 in smokers may be due to the small number of patients considered when the analysis was stratified by smoking status.

To determine whether tiotropium slows the decrease in lung function over time, a 4-year study [29] was performed. Therapy other than inhaled anticholinergic drugs was allowed in accordance with current COPD guidelines. There were no significant differences between study groups in the rate of decline in the mean values for FEV1 and FVC either before or after bronchodilation from day 30 to the end of study (Fig. 7). In the tiotropium group, the mean values for FVC and FEV1 before and after bronchodilation showed significant improvements in FEV1 compared to the placebo group, ranging from 87 to $103 \mathrm{ml}$ before bronchodilation and

b)

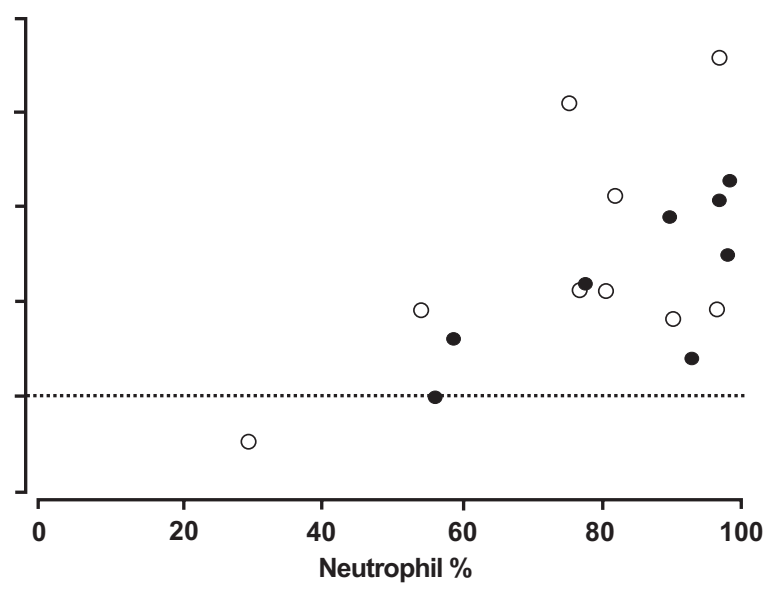

Fig. (8). Spearman rank correlations $\left(r_{s}\right)$ between the change in forced expiratory volume in one-second after 4 weeks of tiotropium bromide administration and (a) eosinophil percentages or (b) neutrophil percentages in induced sputum. Eosinophil and neutrophil percentages were determined prior tiotropium bromide administration. In all subjects (a) $r_{s}=0.669 . p=0.003$ and (b) $r_{s}=0.540$. $p=0.025$. In smokers (a) $r_{s}$ $=0.706 . p=0.034$ and (b) $r_{s}=0.361 . p=0.339$. In nonsmokers (a) $r_{s}=0.762 . p=0.028$ and (b) $r_{s}=0.762 . p=0.028$. $\bigcirc$ smokers; $\bullet$ nonsmokers. From Iwamoto et al. [67]. 
from 47 to $65 \mathrm{ml}$ afterwards. The rate of decline in subgroups analyses showed no significant differences according to age, gender, smoking status, Gold stage and reversibility. In a post hoc analysis, between-group differences in the rate of decline in post-bronchodilator FEV1 were observed, with tiotropium again performing better than placebo $(40 \pm 3 \mathrm{ml}$ in the tiotropium group and $47 \pm 3$ in the placebo group, $p=$ 0.046 ) in the subgroup of 1554 patients who were not receiving either inhaled corticosteroids or LABA at baseline.

Compared with results of previous long-term studies, the rate of decline in FEV1 observed in the UPLIFT study was numerically lower than those reported previously [55-58] and similar to those reported for healthy nonsmokers and sustained quitters with mild-to-moderate COPD [53] (Table 1).

The current treatment for COPD may affect the decline in lung function and may have a ceiling effect, with the result that no further improvements are seen in the absence of an intervention that repairs or regenerates lung tissue [29].

\section{SIDE EFFECTS OF TIOTROPIUM}

Tiotropium has a wide therapeutic margin due to its poor gastrointestinal absorption and thus has very low systemic bioavailability. To date, no unfavorable interactions between tiotropium and other drugs have been reported.

Kesten et al. [59] conducted a pooled analysis of adverse event data on 7819 patients with COPD from 19 randomized, double blind, placebo-control trials with tiotropium. Inherently serious cardiac conditions such as cardiovascular mortality (RR: 057; 95\% CI: 0.26 to 1.26 ), cardiac arrest (RR: 0.90 ; $95 \% \mathrm{CI}: 0.26$ to 3.15 ), and myocardial infarction (RR: $0.74 ; 95 \% \mathrm{CI}: 0.26$ to 2.07$)$ were not more frequent among patients receiving tiotropium than patients receiving placebo. Among heart rate and rhythm disorders, the relative risk of tachycardia (excluding ventricular tachycardia and fibrillation) was 1.68 (95\% CI: 0.69 to 4.11$)$ for any degree of the condition and 1.16 (95\% CI: 0.33 to 0.43 ) for serious tachycardia. The relative risk of left-heart failure among patients receiving tiotropium compared with patients receiving placebo was 0.46 (95\% CI: 0.21 to 1.00$)$. There was no increase in total and serious events due to ischemic heart disease.

For GI disorders, there was a higher risk of dry mouth in patients receiving tiotropium $(\mathrm{RR}, 3.60 ; 95 \% \mathrm{CI}, 2.56$ to $5.05)$, but none was classified as serious. The relative risk of dysphagia was 5.91 (95\% CI, 0.60 to 58.31$)$. There was no increased risk of abdominal pain, constipation, dyspepsia, or nausea associated to tiotropium use.

Among renal and urinary disorders, the relative risk of urinary retention in patients receiving tiotropium compared to placebo was 10.93 (95\% CI: 1.26 to 94.88 ). Although the relative risk of serious prostatic disorders was 5.32 (95\% CI: 0.59 to 48.33 ), the analysis of all selected events showed no association of tiotropium (RR: 1.04 ; $95 \%$ CI: 0.46 to 2.35 ).

As for skin disorders, the relative risk of pruritus in tiotropium users was 1.61 (95\% CI: 0.68 to 3.82$)$. There was no increase in the risk of serious events among these disorders. An analysis of other selected events indicated no increased risk of glaucoma, other visual disturbances, chest pain, edema, fungal infections, musculoskeletal and connective tissue disorders, central nervous system (CNS) or psychiatric disorders.

In UPLIFT study, for all-cause mortality, the relative risk in patients receiving tiotropium compared to patients receiving placebo was 0.76 (95\% CI: 0.50 to 1.16$)$. The relative risk of cardiovascular mortality was 0.57 (95\% CI: 0.26 to $1.26)$ and of respiratory mortality was 0.71 (95\% CI: 0.29 to 1.74).

A recent publication [60] has raised concerns about the safety of tiotropium bromide. Assessing the results of a meta-analysis of 17 previously conducted clinical trials, Singh et al. suggested an association between inhaled anticholinergics and an increased risk of cardiovascular death and myocardial infarction and stroke. However, the methodology of Singh et al.'s study raises several important concerns. First, placebo controlled trials were considered together with active controlled trials, implicitly assuming that the comparator drug is interchangeable with a placebo. Second, the analysis does not take into account the fact that in most trials more patients in the placebo group dropped out than patients taking active medication, and that they were followed for briefer periods of time, during which adverse events were reported. Third, most of the evidence in the analysis is from The Lung Health Study [61], in which most of the cardiovascular deaths occurred among patients who were not using their inhalers; clearly, these deaths could not be due to a medication they were not taking. Finally, the dataset analyzed appears to have an important methodological flaw that potentially invalidates the findings: it appears to include two studies twice, thus double-counting more than one thousand patients.

Table 1. Result of Long-Term Studies in the Rate of Decline in FEV1

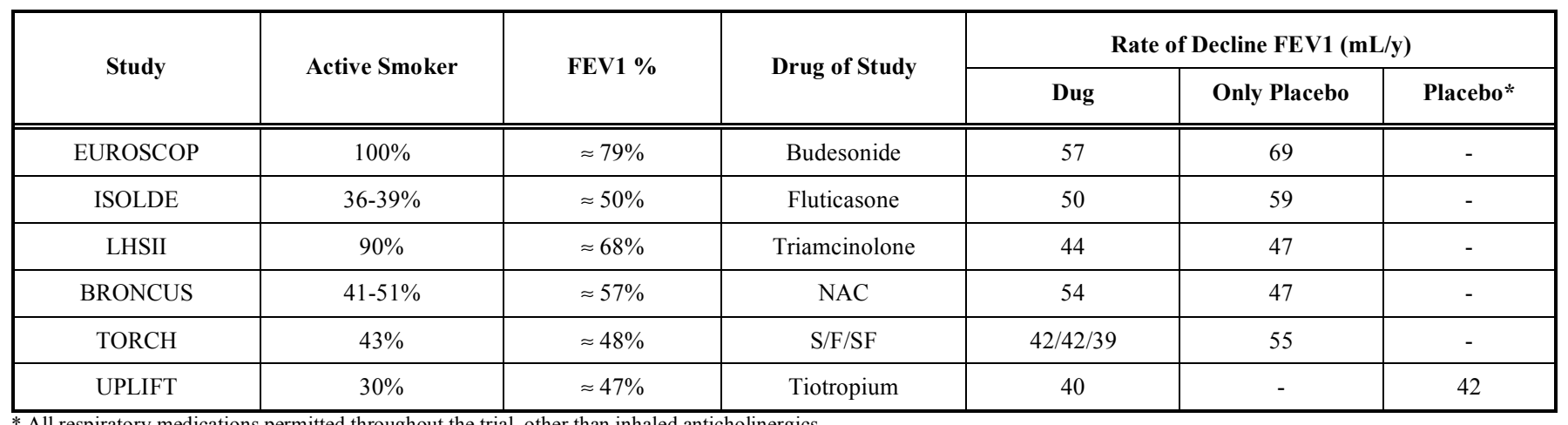

* All respiratory medications permitted throughout the trial, other than inhaled anticholinergics. 
Two recent studies $[29,62]$ found that tiotropium was associated with reduced respiratory and overall mortality and was not associated with increased cardiac mortality. In the UPLIFT study [29], respiratory failure developed in 88 patients in the tiotropium group and in 120 in the placebo group (RR: 0.67 ; $95 \% \mathrm{CI}$ : 0.51 to 0.89 ); myocardial infarction developed in 67 patients in the tiotropium group and in 85 in the placebo group (relative risk, $0.73 ; 95 \%$ CI: 0.53 to 1.00 ) and stroke developed in 82 patients in the tiotropium group and 80 in the placebo group (RR: $0.95 ; 95 \%$ CI: 0.70 to 1.29). In summary, tiotropium seems to reduce the risk of mortality due to cardiac and vascular causes. Furthermore, it does not increase the risk of stroke and it may decrease the risk of myocardial infarction.

\section{THE ROLE OF TIOTROPIUM IN THE MANAGE- MENT OF ASTHMA}

Anticholonergic drugs inhibit reflex cholinergic bronchoconstriction but are unable to significantly block the direct effects of inflammatory mediators such as histamine, kinins and leukotrienes on bronchial smooth muscle. This is why they are less effective bronchodilators in asthma than $\beta_{2}$-agonists. However, in a study of 12 atopic male asthmatic patients, tiotropium provided significant protection against a methacoline challenge for $48 \mathrm{~h}$ [63].

Some subgroups of asthmatics seem to respond better to anticholinergics. Some authors aiming to identify these subgroups have suggested the following clinical profile: patients with nocturnal symptoms, chronic asthma showing concurrent fixed airway obstruction, intrinsic asthma with longer duration of disease and non-atopic asthma [63, 64]. Today, there are three trials that identify patients with asthma who respond to tiotropium:

1. A genotype-stratified study revealed a greater bronchoprotective effect of anticholinergic agents in asthmatic patients with the Arg/Arg genotype of the $\beta 2$-adrenergic receptor [65].

2. COPD and asthma are common and can occur in the same patient. In this case, chronic use of tiotropium achieves spirometric improvements with symptomatic benefits, as seen by reduced need for rescue medication [66].

3. Iwamoto et al. [67] showed an association between responsiveness to tiotropium bromide and the presence of different inflammatory cells in the induced sputum of patients with severe persistent asthma treated with moderateto-high doses of inhaled corticosteroids and other antiasthma agents. The percentages of eosinophils in induced sputum were inversely correlated with $\triangle \mathrm{FEV} 1$, whereas the proportions of neutrophils were positively correlated with $\triangle$ FEV1. Comparable results from nonsmoking asthmatics indicate a rationale for using tiotropium bromide to treat severe patients/with a noneosinophilic sputum profile (Fig. 8).

\section{REFERENCES}

[1] Barnes PJ. Muscarinic receptor subtypes in airways. Life Sci. 1993; 52: $521-7$.

[2] Mak JC, Barnes PJ. Autoradiographic visualization of muscarinic receptor subtypes in human and guinea pig lung. Am Rev Respir Dis 1990; 141: 1559-68.

[3] Eglen RM, Hegde SS, Watson N. Muscarinic receptor subtypes and smooth muscle function. Pharmacol Rev 1996; 48: 531-65.
[4] Patel HJ, Barnes PJ, Tadjkarimi S, Yacoub MH, Belvisi MG. Evidence for prejunctional muscarinic autoreceptors in human and guinea pig trachea. Am J Respir Crit Care Med 1995; 152: 872-8.

[5] Roffel AF, Elzinga CR, Zaagsma J. Muscarinic M3 receptors mediate contraction of human central and peripheral airway smooth muscle. Pulm Pharmacol 1990; 3: 47-51.

[6] Ramnarine SL, Haddad EB, Khawaja AM, Mak JC, Rogers DF. On muscarinic control of neurogenic mucus secretion in ferret trachea. J Physiol 1996; 494: 577-86.

[7] Disse B, Speck GA, Rominger KL, Witek TJ, Jr, Hammer R. Tiotropium (Spiriva): mechanistical considerations and clinical profile in obstructive lung disease. Life Sci 1999; 64: 457-64.

[8] Haddad EB, Mak JC, Barnes PJ. Characterization of $\{3 \mathrm{H}\} 3 \mathrm{Ba} 679 \mathrm{BR}$, a slowly dissociating muscarinic antagonist, in human lung: radioligand binding and autoradiographic mapping. Mol Pharmacol 1994; 45: 899907.

[9] Maessens FPV, Smeets JJ, Sledsens TJH, et al. Tiotropium bromide, a new long-acting antimuscarinic bronchodilator: a pharmacodynamic study in patients with chronic obstructive pulmonary disease. Eur Respir J 1995; 8: 1506-13.

[10] Disse B, Reichl R, Speck G, Traunecker W, Ludwig Rominger KL. Life Sci 1993; 52: 537-544.

[11] Calverly PM, Lee A, Towse L, et al. Effect of tiotropium bromide on circadian variation in airflow limitation in chronic obstructive pulmonary disease. Thorax 2003; 58: 855-60.

[12] Tashkin D, Kesten S. Long-term treatment benefits with tiotropium in COPD patients with and without short-term bronchodilator responses. Chest 2003; 123: 1441-9.

[13] Powrie DJ, Wilkinson TM, Donaldson GC, et al. Effect of tiotropium on sputum and serum inflammatory markers and exacerbations in COPD. Eur Respir J 2007; 30: 472-8.

[14] Pieper MP, Chaudhary NI, Park JE. Acetylcholine-induced proliferation of fibroblast and myofibroblast in vitro is inhibited by tiotropium bromide. Life Sci 2007; 30: 2270-3.

[15] Barnes P. New developments in anticholinergic drugs. Eur Respir Rev 1996; 6: 290-4.

[16] Gross NJA, Skorodins MS. Cholinergic bronchomotor tone in COPD: estimates of its amount in comparison to normal. Chest 1989; 96: 9847.

[17] Barnes PJ. Managing chronic obstructive pulmonary disease, $2^{\text {nd }}$ ed. London: Science Press 2002.

[18] Global Initiative for Chronic Obstructive Lung Disease (GOLD). Guidelines: workshop report. Global Strategy for the Diagnosis, Management, and Prevention of Chronic Obstructive Pulmonary Disease. Updated Setember, 2005. [Date last accessed: January 13, 2007]. Available from: http: //www.goldcop.com/ GuidelineList.asp?!1=2\&!=1

[19] Rodríguez-Carballeira M, Heredia JL, Rué M, Quintana S, Gómez L. The bronchodilator test with increasing doses of terbutaline in chonic obstructive pulmonary disease patients. Pulm Pharmacol Ther 2001; 14: 61-5.

[20] Rodríguez-Carballeira M, Heredia JL, Gómez L, Quintana S, Viñas C. Contribution of ipratropium bromide to the bronchodilator test in patients with chronic obstructive pulmonary disease. Pulm Pharmacol Ther 1999; 12: 43-8.

[21] Rodríguez-Carballeira M, Heredia JL, Rué M, Quintana S, Almagro P. The bronchodilator test in chronic obstructive pulmonary disease: interpretation methods. Respir Med 2007: 101: 34-42.

[22] Tashkin DP, Celli B, Decramer M., Liu D, Burkhart D, Cassino C. Bronchodilator responsiveness in patients with COPD. Eur Respir J. 2008; 31: 742-50.

[23] Littner MR, Ilowite JS, Tashkin DP, et al. Long-acting bronchodilation with once-daily dosing of tiotropium (spiriva) in stable chronic obstructive pulmonary disease. Am J Respir Crit Care Med 2000; 161: 113642.

[24] Van Noord JA, Smeets JJ, Custers FL, et al. Pharmacodynamic steady state of tiotropium in patients with chronic obstructive pulmonary disease. Eur Respir J 2002; 19: 639-44.

[25] Casaburi R, Mahler DA, Jones PW et al. A long-term evaluation of once-daily inhaled tiotropium in chronic obstructive pulmonary disease. Eur Respir J 2002; 19: 217-24.

[26] Vincken W, Van Noord JA, Greefhorst AP, et al. Dutch/Belgian Tiotropium Study Group. Improved health outcomes in patients with COPD during 1year treatment with tiotropium. Eur Respir J 2002; 19: 209-16.

[27] Donohue JF, Van Noord JA, Bateman ED, et al. A 6-month, placebocontrolled study comparing lung function and health status changes in 
COPD patients treated with tiotropium or salmeterol. Chest 2002; 122 : 47-55.

[28] Brusasco V, Hodder R, Miravitlles M, et al. Health outcomes following treatment for six months with once daily tiotropium compared twice daily salmeterol in patients with COPD. Thorax 2003; 58: 399-404.

[29] Tashkin DP, Celi B, Senn S, et al. A 4-year trial of tiotropium in chronic obstructive pulmonary disease. N Engl J Med 2008; 359: 154354.

[30] Cazzola M, Santus P, D’Adda A, Pizzolato S, Di Marco F. Acute effects of higher than standard doses of salbutamol and ipratropium on tiotropium-induced bronchodilation in patients with stable COPD. Pulm Pharmacol Ther 2008. Web/URL PM: 19038356

[31] van Noord JA, Aumann Jl, Janssens E, et al. Effects of tiotropium with and without formoterol on airflow obstruction and resting hyperinflation in patients with COPD. Chest 2006; 129: 509-17.

[32] Aaron SD, Vandemheen KL, Fergusson D, et al. Tiotropium in combination with placebo, salmeterol, or fluticasone-salmeterol for treatment of chronic obstructive pulmonary disease. Annals Int Med 2007; 146: 545-56.

[33] Taube C, Lehnigk B, Paasch K, et al. Factor analysis of changes in dyspnea and lung function parameters after bronchodilation in chronic obstructive pulmonary disease. Am J Respir Crit Care Med 2000; 162 : 216-20.

[34] O'Donell DE, Lam M, Webb KA. Spirometric correlates of improvement in exercise performance after anticholinergic therapy in chronic obstructive pulmonary disease. Am J Respir Crit Care Med 1999; 160: 542-9.

[35] Marin JM, Carrizo SJ, Gascon M, et al. Inspiratory capacity, dynamic hyperinflation, breathlessness, and exercise performance during the 6minute-walk test in chronic obstructive pulmonary disease. Am J Respir Crit Care Med 2001; 63: 1395-9.

[36] Celli B, Zu Wallack R, Wang S, et al. Improvement in resting inspiratory capacity and hyperinflation with tiotropium in COPD patients with increased static lung volumes. Chest 2003; $24: 1743-8$

[37] O'Donnell DE, Flüge T, Gerken F, et al. Effects of tiotropium on lung hyperinflation, dyspnea and exercise tolerance in COPD. Eur Respir J 2004; 23: 832-40.

[38] Gelb AF, Taylor CF, Cassino C, Shinar CM, Schein MJ, Zamel N. Pulm Pharmacol Ther 2009. Web/URL. PM: 19138754

[39] Mahler DA, Weinberg DH, Wells CK, et al. The measurement of dyspnea: contents, interobserver agreement, and physiologic correlates of two new clinical indexes. Chest 1984; 85: 751-8.

[40] British Thoracic Society Standards of Care Subcommittee on pulmonary Rehabilitation. Pulmonary Rehabilitation. Thorax 2001; 56: 82734.

[41] American Thoracic Society. Pulmonary rehabilitation - 1999: official statement of the American Thoracic Society. Am J Respir Crit Care Med 1999; 159: 1666-82.

[42] Casaburi R, Kukafka D, Cooper CB, Witek TJ, Jr, Kesten S. Improvement in exercise tolerance with the combination of tiotropium and pulmonary rehabilitation in patients with COPD. Chest 2005; 127: 809-17.

[43] Almago P, Calbo E, Ochoa de Echagüen A, Barreiro B, Quintana S, Heredia JL. Mortality after hospitalization for COPD. Chest 2002; 121 : 1441-8.

[44] Anthonisen NR, Manfreda J, Warren CP, Hershfield ES, Harding GK, Nelson NA. Antibiotic therapy in exacerbations of chronic obstructive pulmonary disease. Ann Intern Med 1987; 106: 196-204.

[45] Wedzicha JA, Calverly MA, Seemungal TA, Hagan G, Ansari Z, Stockley RA. The prevention of chronic obstructive pulmonary disease exacerbations by salmeterol/ fluticasone propionate or tiotropium bromide. Am J Respir Crit Care Med 2008; 177: 19-26.

[46] Rodrigo GJ, Nannini LJ. Tiotropium for the treatment of stable chronic obstructive pulmonary disease: a systematic review with meta-analysis. Pulm Pharmacol Ther 2007; 20: 495-502.

[47] Barr RG, Bourbeau J, Camargo CA, Ram FS. Tiotropium for stable chronic obstructive pulmonary disease: a meta-analysis. Thorax 2006; 61: 854-62.
[48] Anthonisen NR, Skeans MA, Wise RA, Manfreda J, Kanner RE, Connett JE. The effects of a smoking cessation intervention on 14.5 year mortality: a randomized clinical trial. Ann Intern Med 2005; 142 . 233-239.

[49] Celli BR, Thomas NE, Anderson JA, et al. Effect of pharmacotherapy on rate of decline of lung function in chronic obstructive pulmonary disease: results from the TORCH study. Am J Respir Crit Care Med 2008; 178: 332-8

[50] Suissa S. Methodologic shortcomings of the INSPIRE randomized trial. Am J Respir Crit Care Med 2008: 178: 543-4.

[51] van der Valk P, Monninkhof E, van der Palen J, Zielhuis G, van Herwaarden C. Effect of discontinuation of inhaled corticosteroids in patients with chronic obstructive pulmonary disease: the COPE study. Am J Respir Crit Care Med 2002; 166: 1358-63.

[52] Gershon AS, Wang L, To T, Luo J, Upshur RE. Survival with tiotropium compared to long-acting beta2-agonist in chronic obstructive pulmonary disease. COPD 2008; 5: 229-34.

[53] Anthonissen NR, Connet JE, Kiley JP, et al. Effects of smoking intervention and the use of an inhales anticholinergic bronchodilator on the rate of decline of FEV1: the Lung Health Study. JAMA 1994; 272 : 1497-1505.

[54] Anzueto A, Tashkin D, Menjoge S. One-year analysis of longitudinal changes in spirometry in patients with COPD receiving tiotropium. Pulm Pharmacol Ther 2005; 18: 75-81

[55] The Lung Health Study Research Group. Effect of inhaled triamcinolone on the decline in pulmonary function in chronic obstructive pulmonary disease. N Engl J Med 2000; 343: 1902-9.

[56] Paweles RA, Löfdahl CG, Laitinen LA, et al. Long-term treatment with inhaled budesonide in persons with mild chronic obstructive pulmonary disease who continue smoking. N Engl J Med 1999; 340: 1948-53.

[57] Burge PS, Calverly PM, Jones PW, Spencer S, Anderson JA, Maslen TK. Randomised, double blind placebo controlled study of fluticasone propionate in patients with moderate to severe chronic obstructive pulmonary disease: the ISOLDE trial. BMJ 2000; 320: 1297-303.

[58] Decramer M, Rutten-van Mölken M, Dekhuijzen PN, et al. Effects of $\mathrm{N}$-acetylcysteine on outcomes in chronic obstructive pulmonary disease (Bronchitis Randomized on NAC Cost-Utility Study, BRONCUS): a randomized placebo-controlled trial. Lancet 2005; 365: 1552-60. (Erratum, Lancet 2005; 366: 984).

[59] Kesten S, Jara M, Wentworth C, Lanes S. Pooled clinical trial analysis of tiotropium safety. Chest 2006; 130: 1695- 1703.

[60] Singh S, Loke YK, Furberg CD. Inhaled anticholinergics and risk of major adverse cardiovascular events in patients with chronic obstructive pulmonary disease: a systematic review and meta-analysis. JAMA 2008; 300: 1439-50.

[61] Anthonisen MNR, Connett JE, Enright PF, et al. Hospitalization and mortality in the lung heath study. Am J Respir Crit Care Med 2002; 166: 333-339.

[62] de Luise C, Lanes SF, Jacobsen J, Pedersen L, Sorensen HT. Cardiovascular an respiratory hospitalizations and mortality among users of tiotropium in Denmark. Eur J Epidemiol 2007; 22: 267-72.

[63] O'Connor BJ, Towse LJ, Barnes PJ. Prolonged effect of tiotropium bromide on metacholine-induced bronchoconstriction in asthma. Am J Respir Crit Care Med 1996; 154: 876-80.

[64] Fardon T, Haggart K, Lee DK, Lipworth BJ. A proof of concept study to evaluate stepping down the dose of fluticasone in combination with salmeterol and tiotropium in severe persistent asthma. Respir Med 2007; 101: 1218-28

[65] Kanazawa H. Anticholinergic agents in asthma: chronic bronchodilator therapy, relief of acute severe asthma, reduction of chronic viral inflammation and prevention of airway remodeling. Curr Opin Pulm Med 2006; 12: 60-7.

[66] Magnussen H, Bugnas B, van Noord J, Schmidt P, Gerken F, Kesten S. Improvements with tiotropium in COPD patients with concomitant asthma. Respir Med 2008; 102: 50-6.

[67] Iwamoto H, Yokoyama A, Shiota N, et al. Tiotropium bromide is effective for severe asthma with noneosinophilic phenotype. Eur Respir J 2008; 31: 1379-82.

This is an open access article licensed under the terms of the Creative Commons Attribution Non-Commercial License (http://creativecommons.org/licenses/by$\mathrm{nc} / 3.0 /$ ) which permits unrestricted, non-commercial use, distribution and reproduction in any medium, provided the work is properly cited. 